\title{
BMJ Open Indigenous and non-Indigenous people experiencing homelessness and mental illness in two Canadian cities: A retrospective analysis and implications for culturally informed action
}

To cite: Bingham $B$,

Moniruzzaman A, Patterson M, et al. Indigenous and nonIndigenous people experiencing homelessness and mental illness in two Canadian cities: A retrospective analysis and implications for culturally informed action. BMJ Open 2019;9:e024748. doi:10.1136/ bmjopen-2018-024748

- Prepublication history for this paper is available online. To view these files, please visit the journal online (http://dx.doi org/10.1136/bmjopen-2018024748).

Received 16 June 2018 Revised 30 January 2019 Accepted 12 February 2019

Check for updates

(c) Author(s) (or their employer(s)) 2019. Re-use permitted under CC BY-NC. No commercial re-use. See rights and permissions. Published by BMJ.

${ }^{1}$ Faculty of Health Sciences, Simon Fraser University, Burnaby, British Columbia, Canada

${ }^{2}$ Geography, University of Winnipeg, Winnipeg, Manitoba, Canada

${ }^{3}$ Psychology and Community Health Sciences, University of Manitoba, Winnipeg, Manitoba, Canada

Correspondence to

Brittany Bingham; bld@sfu.ca

\section{ABSTRACT}

Objectives Indigenous people in Canada are not only over-represented among the homeless population but their pathways to homelessness may differ from those of non-Indigenous people. This study investigated the history and current status of Indigenous and nonIndigenous people experiencing homelessness and mental illness. We hypothesised that compared with non-Indigenous people, those who are Indigenous would demonstrate histories of displacement earlier in life, higher rates of trauma and self-medication with alcohol and other substances.

Design and setting Retrospective data were collected from a sample recruited through referral from diverse social and health agencies in Winnipeg and Vancouver. Participants Eligibility included being 19 years or older, current mental disorder and homelessness.

Measures Data were collected via interviews, using questionnaires, on sociodemographics (eg, age, ethnicity, education), mental illness, substance use, physical health, service use and quality of life. Univariate and multivariable models were used to model the association between Indigenous ethnicity and dependent variables.

Results A total of 1010 people met the inclusion criteria, of whom 439 self-identified as Indigenous. In adjusted models, Indigenous ethnicity was independently associated with being homeless at a younger age, having a lifetime duration of homelessness longer than 3 years, post-traumatic stress disorder, less severe mental disorder, alcohol dependence, more severe substance use in the past month and infectious disease. Indigenous participants were also nearly twice as likely as others ( $47 \%$ vs $25 \%$ ) to have children younger than 18 years.

Conclusions Among Canadians who are homeless and mentally ill, those who are Indigenous have distinct histories and current needs that are consistent with the legacy of colonisation. Responses to Indigenous homelessness must be developed within the context of reconciliation between Indigenous and non-Indigenous Canadians, addressing trauma, substance use and family separations.

Trial registration number ISRCTN42520374, ISRCTN57595077, ISRCTN66721740.
Strengths and limitations of this study

- A large sample and validated self-report measures.

- First multisite investigation of distinct needs among Indigenous homeless.

- Demonstration that Indigenous and non-Indigenous homeless individuals have needs that correspond to differences in their historical experiences.

- Symptoms of mental illness and substance use and recollection of past events may have influenced responses.

- Indigenous ethnicity may have been under-reported due to concerns regarding stigma or discrimination.

\section{BACKGROUND}

Indigenous (The term 'Indigenous' will be used throughout this paper to collectively describe the Indigenous peoples of Canada, inclusive of those who identify as 'Aboriginal' or First Nations, Métis and Inuit. This term is used while also acknowledging the diversity of cultures, languages and traditions that exist among Indigenous Canadians) people are over-represented among homeless populations in every part of the world where these rates are documented. ${ }^{1}$ Indigenous people struggling with mental illness, substance use or homelessness often share experiences involving structural inequities and trauma related to colonisation. Despite a visible presence of Indigenous peoples in the urban homeless populations of North America, Australia and New Zealand, there is limited research investigating the prevalence and causes of Indigenous homelessness. ${ }^{1}$ Indigenous Australians comprise 9\% of the homeless population compared with $3.3 \%$ of the general population. Similarly, in New Zealand, Maori homelessness has been reported to be five times that of non-Maori. ${ }^{1}$ 
In Canada, homelessness among Indigenous people is eight times more prevalent than among all others. ${ }^{2}$ Indigenous people comprise about $6 \%$ of British Columbia's population, yet in 2018 accounted for $40 \%$ of Vancouver's homeless of whom close to half are unsheltered $(46 \%){ }^{3}$ The Vancouver area is home to approximately 62000 Indigenous people representing 23\% of B.C.'s Indigenous population. ${ }^{4}$ Women accounted for $53 \%$ of the Indigenous homeless people in Vancouver, and $46 \%$ were under $25 .{ }^{3}$ Homelessness among youth has increased in Vancouver, with those under 25 representing $24 \%$ of the overall homeless population. ${ }^{5}$

Pathways to homelessness integrate poverty, mental illness, addiction, lack of affordable housing and socioeconomic inequities. ${ }^{6-8}$ The high prevalence of mental illness among the homeless ${ }^{9}{ }^{10}$ is related to sustained disinvestment in institutional models of care and insufficient attention to the design and implementation of community-based approaches to delivering housing and support. ${ }^{11}$ Fragmentation between systems responsible for healthcare and social services amplifies the challenges faced by people who are mentally ill and homeless. ${ }^{10}$ Many marginalised and homeless people must navigate a maze of multiple systems to receive essential supports, leading one scholar to describe them as 'system survivors'.$^{10}$ Multidisciplinary models integrating primary care and specialised services have been recommended for people with multiple and complex needs. ${ }^{12}$

Indigenous pathways to homelessness are likely inclusive of the above factors. In addition, current inequities in the health of Indigenous peoples are directly related to past and present colonial policies that created and sustain systemic racism, cultural oppression, disempowerment and dispossession of Indigenous peoples lands. ${ }^{2613}$ The Indian Act (1876) and related policies served to dispossess Indigenous peoples of land, disrupt the practice and transmission of traditional knowledge, undermine the matriarchal role of women and remove generations of children from their communities into settings where abuse was widespread. Canada's Truth and Reconciliation Commission (TRC) identified the residential school era as the beginning of intergenerational cycles of trauma for Indigenous Canadians, ${ }^{14} 15$ and concluded that the actions are taken under the Indian Act and related policies amounted to 'cultural genocide'. ${ }^{14}$

Child welfare policies continue to separate Indigenous children from their families and communities. Indigenous youth are vastly over-represented in the child welfare system and foster care, disrupting Indigenous families and contributing to homelessness. ${ }^{2}$ In Canada, Indigenous children and youth are 15 times more likely to be in government care than non-Indigenous children and youth. ${ }^{15}$ The " 60 s scoop refers to a time at the height of the residential school era in the ' 50 s and ' 60 s, where an amendment to the Canadian Indian Act gave provinces authority over their child protection policies, leading to a dramatic increase in the number of Indigenous children in the child welfare system. Trauma arising from these experiences affects communities across generations. ${ }^{15}$

These differences have led to the development of a distinct definition of Indigenous homelessness in Canada: "Unlike the common colonialist definition of homelessness, Indigenous homelessness is not defined as lacking a structure of habitation; rather, it is more fully described and understood through a composite lens of Indigenous worldviews. These include: individuals, families and communities isolated from their relationships to land, water, place, family, kin, each other, animals, cultures, languages and identities. Importantly, Indigenous people experiencing these kinds of homelessness cannot culturally, spiritually, emotionally or physically reconnect with their indigeneity or lost relationships'. ${ }^{16}$ A related insight can be found in the final report of the TRC, which examined the urgent and complex relationships between Indigenous and non-Indigenous peoples in Canada and does not mention the term 'homelessness' at all, but includes the term 'home' 146 times, usually in the context of loss and enforced separation. ${ }^{14}$

Among relevant empirical studies, disparities have been reported concerning Indigenous peoples' access to appropriate and responsive primary healthcare. ${ }^{17-19}$ Pervasive racism and discrimination against Indigenous peoples in the Canadian healthcare system has been widely reported and in many cases has led to Indigenous patients strategising for how to avoid racism before seeking care or avoiding care altogether. ${ }^{17}{ }^{20}$ Despite the high need $(\mathrm{HN})$ for mental health, substance use and healthcare among homeless populations there remain substantial gaps in research examining the implications of historical and current differences between Indigenous and non-Indigenous peoples as they relate to policies and services addressing homelessness. The need for further research into the effects of ethnicity on homelessness has been well established. ${ }^{21}$ Indeed, few studies have examined the potential upstream causal factors that contribute to the over-representation of Indigenous people among the homeless. ${ }^{1}$ Such information is essential to the development of effective policies.

The current study investigated differences between Indigenous and non-Indigenous people who experienced homelessness and mental illness, and whether differences are consistent with distinct trajectories leading to homelessness. We hypothesised that Indigenous participants would be more likely to have experienced homelessness earlier in life and have higher prevalence of trauma and substance use, and that non-Indigenous participants would be more likely to experience serious mental illness such as schizophrenia.

\section{METHODS}

\section{Data source and sample}

The At Home/Chez Soi Study took place in five Canadian cities and enrolled participants who were homeless and mentally ill. ${ }^{22} 23$ The current study includes baseline data 
from Vancouver and Winnipeg, the sites with the highest proportions of Indigenous people who are homeless. Further details related to the trial protocols and methods that are not essential to the current study have been published elsewhere. ${ }^{22} 23$

Eligibility criteria included being a legal adult (19 years or older), current mental disorder and being absolutely or precariously housed. Absolute homelessness was defined as having no place to stay for more than seven nights and little likelihood of finding a place in the next month. ${ }^{22}$ Precarious housing referred to living in a rooming house, hotel or transitional housing and having at least two episodes of homelessness, as defined above, in the past year. ${ }^{22}{ }^{23}$ Participants were recruited through referral from diverse agencies including: homeless shelters; drop-in centres; homeless outreach teams; hospitals; community mental health team and criminal justice programmes. Organisations that serve women, youth, Indigenous peoples and gay/lesbian/transgender were targeted to obtain a diverse sample.

An initial face-to-face interview was conducted to determine if referred individuals met the inclusion criteria. On meeting criteria, participants completed written informed consent obtained by the interviewer and were enrolled and administered the baseline questionnaire that included information on sociodemographics, mental illness, substance use, physical health, service use and quality of life. Participants were not eligible for recruitment if they could not give informed consent. Consent procedures were tested prior to study implementation ${ }^{24}$ and interviewers were trained by senior clinicians with ongoing support from a clinical psychologist and psychiatry resident. Interviews were postponed or rescheduled if a participant was unable to give informed consent to the study details (eg, randomisation) for any reason. ${ }^{23}$ Participants received a cash honorarium of US $\$ 30$ on completion of the baseline interview and US $\$ 20$ for each subsequent interview. Results are based on data from the baseline questionnaires of 497 Vancouver participants and 513 Winnipeg participants.

\section{Patient and public involvement}

Indigenous people and community stakeholders were engaged in the development and implementation of this research. Community meetings (including advertised open meetings) and six focus groups were conducted with key informants. ${ }^{23}$ In total, 58 individuals were convened and met with a facilitator who prepared reports of the proceedings. Focus group participants advised on procedures, reducing risks and maximising benefits to participants and on how to incorporate the expertise of individuals with direct experience of homelessness into the study. Narrative feedback from participants was incorporated into the grant application and the project. Service providers were also consulted extensively during the design of the research. More specifically, in Winnipeg, where Indigenous homelessness was a specific focus, an Indigenous research steering committee was created, composed of elders and traditional teachers, to provide cultural advice and guidance to the research team to ensure that Indigenous perspectives were incorporated. In addition, a Lived Experience Circle was created which honoured and promoted Indigenous lived experience through the research. In Winnipeg, persons with lived experience (PWLE) were involved in multiple roles on the project as representatives on an advisory committee and employed as research staff. PWLE assisted in facilitating integrated knowledge exchange, working with staff of the interventions and directly to bring patient perspectives into the research and interventions. Since completion of the trial, across all study sites findings have been reported at a variety of academic forums distributed to diverse audiences including provincial governments, municipalities, health authorities and community agencies. In April 2018, a forum was held where key members of community service organisations that work with Indigenous people who are homeless were invited to review study results, provide their recommendations and guide the interpretation of meaning. The current findings will be disseminated following publication via the established network of local service providers, stakeholders and participants of the research forum.

\section{Variables of interest}

Indigenous or Aboriginal ethnicity status was derived from self-report. Participants were asked if they identify as 'Aboriginal' and to check all that apply: Inuit, Métis, First Nations status, First Nations non-status, Indigenous from outside Canada and other. For the purposes of these analyses, participants who identified as any of these categories of 'Aboriginal' were considered to be Indigenous. The cluster of severe mental disorders includes at least one of current (ie, past month) psychotic disorder, mood disorder with psychotic features and hypomanic or manic episode, as identified through the MINI International Neuropsychiatric Interview 6.0 (MINI) ${ }^{25}$ The MINI is a structured, short diagnostic interview often used for psychiatric evaluation and outcome tracking, with an administrative time of about $15 \mathrm{~min}$. The less severe cluster includes at least one of current major depressive episode, panic disorder and post-traumatic stress disorder (PTSD). In addition, diagnosis of alcohol and substance dependence was assessed determined using the MINI. Substance use severity in the past month was assessed using the Global Assessment of Individual Need-Substance Problem Scale, a 16-item subscale that integrates research and clinical assessment for people presenting for substance abuse treatment. ${ }^{22}$ Frequency of use included all illicit drugs and alcohol. Bloodborne infectious disease was based on a positive self-report diagnosis of HIV, hepatitis B or hepatitis C. Self-reported involvement with health services was collected for the past 6 months including visiting a: family doctor, psychiatrist, emergency room (ER) and being transported by ambulance to an ER. Access to healthcare was elicited by the questions 'Is there a place that you usually go to when you're sick or in need of advice about your 
health?' and 'In the past 6 months, was there ever a time when you needed healthcare but you did not receive it?' Criminal justice services included: Contact with the police that did not result in arrest; contacts that resulted in arrest; or being held in a police cell for less than 24 hours. Rates of imprisonment were not differentiated from this item. However, further analysis of administrative records for the Vancouver sample found that $14 \%$ had been in custody during the 6 months prior to study recruitment. ${ }^{26}$ Participants were categorised as either moderate needs (MN) or $\mathrm{HN}$ ). Inclusion in the HN category was based on a score of 62 or lower on the Multnomah Community Ability Scale (MCAS) or current bipolar or psychotic disorder as well as one of the following: legal involvement in the past year; substance dependence in the past month and two or more hospitalisations for mental illness in the past 5 years. ${ }^{27}$ All other eligible participants were categorised as $\mathrm{MN}$ in the study. ${ }^{22}$ The MCAS is a 17 -item scale measuring the degree of functional ability through 17 indicators. Indicators are rated into a 5-point scale across health, coping, social and behavioural domains. Detailed descriptions and psychometric information for study instruments is published in the At Home/Chez Soi Trial protocol. ${ }^{22}$

\section{Statistical analysis}

Pearson $\chi^{2}$ or Fisher's exact test were used to conduct comparisons between baseline sociodemographic characteristics for Vancouver and Winnipeg participants and to make comparisons between Indigenous and non-Indigenous participants. Comparisons of numeric variables (eg, age at enrolment) between groups were conducted using the Student's t-test and Wilcoxon rank-sum test. Comparisons were conducted across sociodemographic variables, homelessness variables, mental health, substance use, health conditions and service use for individuals of Indigenous versus non-Indigenous ethnicity. Univariate and multivariate logistic regression analyses were used to model the independent associations between Indigenous ethnicity and a series of outcome variables. Statistical significance (variables that were significant at the $\mathrm{p}<0.05$ level), as well as subjective assessment, was considered to select outcome variables for the multivariable logistic regression analyses. The multivariable model adjusted for potentially confounding variables which may have been unevenly distributed based on ethnicity. ${ }^{232}$ The following controlling variables were used for the multivariable model: age (continuous); gender (man, woman); need level (high, moderate); marital status (single, other); site (Vancouver, Winnipeg); education (completed high school, incomplete high school); have children (under age 18). Both unadjusted and adjusted odds ratios (UOR and AOR) and 95\% CIs are reported. SPSS V.21 was used to conduct these analyses.

\section{RESULTS}

Descriptive characteristics of participants recruited in Vancouver $(n=497)$ and Winnipeg $(n=513)$ are presented in table 1. In Vancouver, the mean age of participants was 41 years $(\mathrm{SD}=11)$ and the majority were male $(73 \%)$, white $(56 \%)$, single/never married $(70 \%)$ and had not completed high school (57\%). In Winnipeg, the mean age of participants $(\mathrm{n}=513)$ was 39 years $(\mathrm{SD}=11)$ and the majority were male $(64 \%)$, Indigenous $(71 \%)$, single/ never married $(70 \%)$ and had not completed high school (69\%). Participants at the Vancouver and Winnipeg sites significantly differed with respect to: need level; gender; ethnicity; education; hospitalisations; arrests; housing status; mental illness severity and suicidality $(\mathrm{p}<0.05)$.

Univariate comparisons between Indigenous (439) and non-Indigenous (571) samples from both study sites are presented in table 2. The majority of Indigenous participants met criteria for the MN condition (59\%), were male $(61 \%)$, had not completed high school $(75 \%)$ and had a lifetime duration of homelessness greater than 3 years (52\%). Compared with non-Indigenous participants, Indigenous participants were more likely to have children under the age of $18(52 \%$ vs $25 \%)$ and were first homeless at a younger age (63\% vs $51 \%$ reporting being first homeless before the age of 30).

Effect size estimates as (UOR and AOR) and 95\% CIs are presented in table 3 . Results from multivariable logistic regression analyses indicate that self-reported Indigenous ethnicity independently predicted a younger age first homeless $<25$ years (AOR 1.56; 95\% CI 1.06 to 2.27), a longer lifetime duration of homelessness (more than 3 years) (AOR 1.41; 95\% CI 1.01 to 2.0), PTSD (AOR 1.91; 95\% CI 1.35 to 2.70), not meeting criteria for 'severe' mental disorder (AOR 1.72; 95\% CI 1.16 to 2.56), alcohol dependence (AOR 2.64, 95\% CI 1.90 to 3.68), more severe substance use in the past month (AOR 2.43; 95\% CI 1.67 to 3.56 ) and infectious bloodborne diseases (AOR 1.59; 95\% CI 1.08 to 2.34).

\section{DISCUSSION}

Our findings suggest that the trajectories leading to homelessness among Indigenous and non-Indigenous people differ meaningfully from each other, and that they can be understood as consequences of harmful government policies. Consistent with the legacy of colonisation and cultural genocide, when compared with others, Indigenous participants experienced homelessness and first used substances at a younger age, spent more of their lives living homeless, were more frequently taken by ambulance to hospital and were more likely to meet criteria for PTSD, severe substance use and have an infectious disease. Conversely, non-Indigenous participants were more likely to meet criteria for schizophrenia or other severe mental illness, suggesting links to deinstitutionalisation and the inadequate implementation of alternative community-based treatment. These differences require consideration in the development of culturally appropriate housing and support services that are specific to the needs of Indigenous and non-Indigenous peoples. Programmes for Indigenous people must prevent homelessness early in life, stemming the grossly 
Table 1 Sociodemographic, mental health, substance use and service use characteristics for Vancouver and Winnipeg At Home Study participants $(n=1010)$

\begin{tabular}{|c|c|c|c|}
\hline Variable & $\begin{array}{l}\text { Vancouver Site } \\
\text { N (\%) } \\
497(49.2)\end{array}$ & $\begin{array}{l}\text { Winnipeg Site } \\
\text { N (\%) } \\
513(50.8)\end{array}$ & $P$ value \\
\hline \multicolumn{4}{|l|}{ Need level } \\
\hline High need & $297(59.8)$ & $199(38.8)$ & \multirow[t]{2}{*}{$<0.001$} \\
\hline Moderate need & $200(40.2)$ & $314(61.2)$ & \\
\hline \multicolumn{4}{|l|}{ Gender } \\
\hline Male & $359(72.8)$ & $326(63.8)$ & \multirow[t]{2}{*}{0.002} \\
\hline Female & $134(27.2)$ & $185(36.2)$ & \\
\hline \multicolumn{4}{|l|}{ Age at enrolment } \\
\hline Youth & $36(7.2)$ & $64(12.5)$ & \multirow[t]{3}{*}{0.020} \\
\hline $25-44$ years & $281(56.5)$ & $277(54.0)$ & \\
\hline 44 plus years & $180(36.2)$ & $172(33.5)$ & \\
\hline \multicolumn{4}{|l|}{ Ethnicity } \\
\hline Indigenous & 77 (15.5) & $362(70.6)$ & \multirow[t]{3}{*}{$<0.001$} \\
\hline White & $280(56.3)$ & $112(21.8)$ & \\
\hline Mixed/other & $140(28.2)$ & $39(7.6)$ & \\
\hline \multicolumn{4}{|l|}{ Education } \\
\hline High school or higher & $214(43.3)$ & $157(30.7)$ & \multirow[t]{2}{*}{$<0.001$} \\
\hline Less than high school & $280(56.7)$ & $354(69.3)$ & \\
\hline \multicolumn{4}{|l|}{ Marital status } \\
\hline Single (never married) & $343(69.6)$ & $359(70.3)$ & \multirow[t]{3}{*}{0.971} \\
\hline Married/partner & $25(5.1)$ & $25(4.9)$ & \\
\hline Separated/widow/divorced & $125(25.4)$ & $127(24.9)$ & \\
\hline Have children (under 18) & $122(25.1)$ & $238(47.1)$ & $<0.001$ \\
\hline Hospitalised for mental illness over 6 months in past 5 years & $57(11.7)$ & $23(4.5)$ & $<0.001$ \\
\hline Hospitalised for mental illness over two times in the past 5 years & $253(52.7)$ & $111(21.9)$ & $<0.001$ \\
\hline Arrested/imprisoned/probation/community sanction in past 6 months & $221(45.2)$ & $179(35.0)$ & 0.001 \\
\hline Spend one or more night in hospital, detox, shelter and jail in past 6 months & $65(84.4)$ & $321(88.7)$ & 0.298 \\
\hline \multicolumn{4}{|l|}{ Length of homelessness lifetime } \\
\hline $1-3$ years & $257(52.3)$ & $262(53.0)$ & \multirow[t]{2}{*}{0.827} \\
\hline 3years plus & $234(47.7)$ & $232(47.0)$ & \\
\hline \multicolumn{4}{|l|}{ Length of homelessness longest single period } \\
\hline 12 months & $246(50.1)$ & $227(46.9)$ & \multirow[t]{3}{*}{0.317} \\
\hline $13-60$ months & $182(37.1)$ & $192(39.7)$ & \\
\hline 60 months plus & 63 (12.8) & 65 (13.4) & \\
\hline \multicolumn{4}{|l|}{ Age first homeless } \\
\hline 18 years or less & $110(22.4)$ & $138(27.2)$ & \multirow[t]{4}{*}{0.173} \\
\hline 19-30years & $158(32.2)$ & $151(29.8)$ & \\
\hline $31-40$ years & $94(19.1)$ & $106(20.9)$ & \\
\hline Over 40 years & 129 (26.3) & $112(22.1)$ & \\
\hline \multicolumn{4}{|l|}{ Housing status } \\
\hline Absolutely homeless & $388(78.1)$ & $354(69.1)$ & \multirow[t]{2}{*}{0.001} \\
\hline Precariously housed & 109 (21.9) & $158(30.9)$ & \\
\hline \multicolumn{4}{|l|}{ Mental illness } \\
\hline Less severe mental illness & $264(53.1)$ & $436(85.0)$ & $<0.001$ \\
\hline
\end{tabular}


Table 1 Continued

\begin{tabular}{|c|c|c|c|}
\hline Variable & $\begin{array}{l}\text { Vancouver Site } \\
N(\%) \\
497(49.2)\end{array}$ & $\begin{array}{l}\text { Winnipeg Site } \\
\text { N (\%) } \\
513(50.8)\end{array}$ & $P$ value \\
\hline Multiple mental disorders $(\geq 2)$ & $240(48.3)$ & 338 (65.9) & $<0.001$ \\
\hline Post-traumatic stress disorder & $129(26.0)$ & $233(45.4)$ & $<0.001$ \\
\hline Current suicidality (high) & $373(75.1)$ & $447(87.1)$ & $<0.001$ \\
\hline \multicolumn{4}{|l|}{ Chronic disease and service access } \\
\hline Bloodborne diseases & $157(31.9)$ & $113(22.2)$ & 0.001 \\
\hline Two or more physical illness & $402(80.9)$ & $458(89.3)$ & $<0.001$ \\
\hline Have a regular medical doctor & $320(64.5)$ & $337(65.7)$ & 0.695 \\
\hline Place you usually go when you are sick or need advice about your health & $395(80.8)$ & $430(84.1)$ & 0.161 \\
\hline Needed healthcare, but did not receive it in past 6 months & $209(43.2)$ & $278(55.0)$ & $<0.001$ \\
\hline \multicolumn{4}{|l|}{ Substance use } \\
\hline Current alcohol dependence & $29(37.7)$ & $261(72.1)$ & $<0.001$ \\
\hline Current substance dependence & $57(74.0)$ & $183(50.6)$ & $<0.001$ \\
\hline \multirow[t]{2}{*}{ Age first alcohol use (categorised by median) $(\geq 14 ;<13)$} & $33(44.0)$ & $140(39.9)$ & 0.510 \\
\hline & $42(56.0)$ & $211(60.1)$ & \\
\hline \multirow[t]{2}{*}{ Age first drug use (After $>14 ;<13$ ) } & $37(49.3)$ & $160(47.1)$ & 0.721 \\
\hline & $38(50.7)$ & $180(52.9)$ & \\
\hline \multirow{2}{*}{$\begin{array}{l}\text { Global Assessment of Individual Need score ( } 0-3 \text { less severe); ( } 4-5 \text { severe) } \\
\text { substance use in past month }\end{array}$} & $34(48.6)$ & $214(62.8)$ & 0.027 \\
\hline & $36(51.4)$ & $127(37.2)$ & \\
\hline
\end{tabular}

disproportionate rates of removal of Indigenous children and youth into state-administered foster care. ${ }^{1529}$

Within our sample of Indigenous people, we found that almost half of the participants met criteria for PTSD (49\% compared with $26 \%$ among non-Indigenous), consistent with a significant body of literature documenting the historical and continuing trauma experienced by Indigenous people in Canada. ${ }^{5031}$ Bombay et $a l^{31}$ proposed that trauma can be transmitted across generations, based on findings that children of trauma survivors were more likely to have negative responses to stressors and more likely to develop PTSD or depression as a result. ${ }^{3031}$ Intergenerational trauma represents a complex subtype of PTSD that must be addressed in housing interventions for Indigenous people.

Indigenous homeless participants in our study were significantly more likely to have used drugs at a younger age (13 years) compared with non-Indigenous participants. Indigenous participants were also more likely to report severe substance use in the past month. These findings are consistent with research involving non-homeless samples and showing that Indigenous youth compared with non-Indigenous youth have a higher likelihood of experimenting with substances at a younger age and using substances persistently into adulthood. ${ }^{32} 33$ Early initiation into drug use poses a significant risk for adverse outcomes such as infectious disease and other morbidity or mortality. Youth who initiated injection drug use at an earlier age have been found to be more likely to become infected with HIV and hepatitis C, demonstrating the need for targeted and early intervention for youth at risk of drug use. ${ }^{34}$ Observers have consistently reported that Indigenous youth are at disproportionately high risk for problematic substance use. However, few studies have investigated the protective factors related to substance use trajectories for Indigenous youth. ${ }^{35}$ Mainstream substance use treatment models have demonstrated limited success for Indigenous people. ${ }^{36}$ This may be because the factors responsible for substance use, (as well as homelessness and trauma) are unique to the experience of Indigenous people, and require 'treatments' that restore and rebuild Indigenous culture and rights. Approaches that create reconnection to community, culture and traditions have been shown to have a positive impact on substance use. ${ }^{36}$ Rawana and $\mathrm{Ames}^{35}$ reported that optimism, participation in recreational activities and attendance at religious or spiritual services were found to be protective against alcohol misuse for Indigenous youth. Prevention and early intervention of problematic substance use among Indigenous youth is urgently required in on-reserve and urban settings. Culturally, relevant curricula increased access to psychosocial supports, youth recreation and peer support models and trauma-informed services are also required.

In 2016 in the Metro Vancouver homeless count, homeless youth had increased to the highest level recorded in the region with 397 , or $24 \%$ of the overall homeless population, under the age of 25 . Youth reported that they had been affected by the lack of youth services or cuts to youth programmes from one or more levels of government. ${ }^{37}$ 
Table 2 Sociodemographic, mental health, substance use and service use characteristics for Vancouver and Winnipeg At Home Study participants by Indigenous ethnicity $(n=1010)$

\begin{tabular}{|c|c|c|c|}
\hline Variable & $\begin{array}{l}\text { Indigenous } \\
\mathrm{N}(\%) \\
439(43.5 \%)\end{array}$ & $\begin{array}{l}\text { Non-Indigenous } \\
\text { N (\%) } \\
571(56.5 \%)\end{array}$ & $P$ value \\
\hline \multicolumn{4}{|l|}{ Need level } \\
\hline High need & $180(41.0)$ & $316(55.3)$ & \multirow[t]{2}{*}{$<0.001$} \\
\hline Moderate need & $259(59.0)$ & $255(44.7)$ & \\
\hline \multicolumn{4}{|l|}{ Gender } \\
\hline Male & $265(61.1)$ & $420(73.7)$ & \multirow[t]{2}{*}{$<0.001$} \\
\hline Female & 169 (38.9) & $150(26.3)$ & \\
\hline \multicolumn{4}{|l|}{ Age at enrolment } \\
\hline Youth & $53(12.1)$ & $47(8.2)$ & \multirow[t]{3}{*}{0.043} \\
\hline 25-44 Years & $266(60.6)$ & $292(51.1)$ & \\
\hline 44 plus years & $120(27.3)$ & $232(40.6)$ & \\
\hline \multicolumn{4}{|l|}{ Education } \\
\hline High school or higher & $110(25.2)$ & $261(46.0)$ & \multirow[t]{2}{*}{$<0.001$} \\
\hline Less than high school & $327(74.8)$ & $307(54.0)$ & \\
\hline \multicolumn{4}{|l|}{ Marital status } \\
\hline Single (never married) & $313(71.6)$ & $389(68.6)$ & \multirow[t]{3}{*}{0.018} \\
\hline Married/partner & $29(6.6)$ & $21(3.7)$ & \\
\hline Separated/widow/divorced & $95(21.7)$ & $157(27.7)$ & \\
\hline Have children (under 18) & $222(51.5)$ & $138(24.6)$ & $<0.001$ \\
\hline Hospitalised for mental illness over 6 months in past 5 years & $22(5.1)$ & $58(10.3)$ & 0.003 \\
\hline Hospitalised for mental illness over two times in the past 5 years & $107(24.7)$ & $257(46.5)$ & $<0.001$ \\
\hline Arrested/imprisoned/probation/community sanction in past 6 months & $171(39.0)$ & $229(40.7)$ & 0.585 \\
\hline Spent one or more nights in hospital, detox, shelter and jail in past 6 months & $386(87.9)$ & $510(89.6)$ & 0.393 \\
\hline \multicolumn{4}{|l|}{ Length of homelessness lifetime } \\
\hline $1-3$ years & $205(48.3)$ & $314(56.0)$ & \multirow[t]{2}{*}{0.018} \\
\hline 3 years plus & $219(51.7)$ & $247(44.0)$ & \\
\hline \multicolumn{4}{|l|}{ Length of homelessness longest single period } \\
\hline 12 months & $189(45.2)$ & $284(51.0)$ & \multirow[t]{3}{*}{0.074} \\
\hline $13-60$ months & $166(39.7)$ & $208(37.3)$ & \\
\hline 60 months plus & $63(15.1)$ & $65(11.7)$ & \\
\hline \multicolumn{4}{|l|}{ Age first homeless } \\
\hline 18 years or less & $130(30.0)$ & $118(20.9)$ & \multirow[t]{4}{*}{$<0.001$} \\
\hline 19-30years & $142(32.7)$ & 167 (29.6) & \\
\hline $31-40$ years & $86(19.8)$ & $114(20.2)$ & \\
\hline Over 40 years & $76(17.5)$ & $165(29.3)$ & \\
\hline \multicolumn{4}{|l|}{ Housing status } \\
\hline Absolutely homeless & $309(70.4)$ & $433(76.0)$ & \multirow[t]{2}{*}{0.046} \\
\hline Precariously housed & $130(29.6)$ & $137(24.0)$ & \\
\hline \multicolumn{4}{|l|}{ Mental illness } \\
\hline Less severe mental illness & $370(84.3)$ & $330(57.8)$ & $<0.001$ \\
\hline Multiple mental disorders $(\geq 2)$ & $290(66.1)$ & $288(50.4)$ & $<0.001$ \\
\hline Post-traumatic stress disorder & $215(49.0)$ & $147(25.8)$ & $<0.001$ \\
\hline Current suicidality (high) & $381(86.8)$ & 439 (76.9) & $<0.001$ \\
\hline Chronic disease and service access & & & \\
\hline
\end{tabular}


Table 2 Continued

\begin{tabular}{|c|c|c|c|}
\hline Variable & $\begin{array}{l}\text { Indigenous } \\
\mathrm{N}(\%) \\
439(43.5 \%)\end{array}$ & $\begin{array}{l}\text { Non-Indigenous } \\
\text { N (\%) } \\
\mathbf{5 7 1}(56.5 \%)\end{array}$ & $P$ value \\
\hline Bloodborne diseases & $122(28.1)$ & $148(26.1)$ & 0.488 \\
\hline Two or more physical illness & $389(88.6)$ & $471(82.5)$ & 0.007 \\
\hline Have a regular medical doctor & $299(68.1)$ & $358(62.8)$ & 0.080 \\
\hline Place you usually go when you are sick or need advice about your health & $373(85.4)$ & $452(80.3)$ & 0.036 \\
\hline Needed healthcare, but did not receive it in past 6 months & $224(51.7)$ & $263(47.3)$ & 0.167 \\
\hline \multicolumn{4}{|l|}{ Substance use } \\
\hline Current alcohol dependence & $290(66.1)$ & $153(26.8)$ & $<0.001$ \\
\hline Current substance dependence & $240(54.7)$ & $289(50.6)$ & 0.201 \\
\hline \multirow[t]{2}{*}{ Age first alcohol use (categorised by median) $(\geq 14 ;<13)$} & $173(40.6)$ & $301(55.4)$ & $<0.001$ \\
\hline & $253(59.4)$ & $242(44.6)$ & \\
\hline \multirow[t]{2}{*}{ Age first drug use (After $>14 ;<13$ ) } & $197(47.5)$ & $327(63.1)$ & $<0.001$ \\
\hline & $218(52.5)$ & $191(36.9)$ & \\
\hline \multirow{2}{*}{$\begin{array}{l}\text { Global Assessment of Individual Need score ( } 0-3 \text { less severe); ( } 4-5 \text { severe) } \\
\text { substance use in past month }\end{array}$} & $248(60.3)$ & $405(75.4)$ & $<0.001$ \\
\hline & $163(39.7)$ & 132 (24.6) & \\
\hline
\end{tabular}

Street-involved youth often fall between services tailored to children or adults, and this issue is further complicated for Indigenous youth in the child welfare system who age out of many system supports on adulthood. ${ }^{28}{ }^{38}$ Developmental resources grounded in Indigenous cultural practices are required to prevent homelessness among youth who are transitioning from foster care settings and also to support youth who experienced trauma in foster care settings. ${ }^{28} 38$

Indigenous participants in both sites were significantly more likely than non-Indigenous people to have a regular medical doctor and were also more likely to have been taken to the hospital by an ambulance in the past 6 months. This seemingly contradictory finding may indicate that medical care alone is insufficient to prevent acute emergencies caused by environmental, social and historical harms. Moreover, ER visits may be for reasons other than those typically addressed in a primary care setting such as acute psychotic symptoms, overdose, acute trauma and other serious health complications caused by long-term homelessness. Further research is required to investigate the impact of stigma and discrimination on service utilisation for Indigenous people who are homeless and the need for culturally safe services for this population.

The use of ambulance services for those who are homeless and mentally ill is indicative of the lack of essential supports to sustain wellness. Consistent with research with non-homeless samples, we found that Indigenous participants were more likely than non-Indigenous people to report positive status for HIV, hepatitis C or hepatitis B Virus. ${ }^{3940}$ Marshall et al examined HIV prevalence among street-involved youth and found that Indigenous ethnicity was a correlate of HIV infection and that hepatitis C coinfection was less common among Indigenous participants. ${ }^{39}$ Indigenous people also face disparities in HIV outcomes and treatment, as they are likely to be diagnosed and initiate treatment later than non-Indigenous patients. Indigenous people have been noted to suffer higher mortality even after receiving antiretroviral treatment, suggesting that social determinants may need to be addressed in order to realise the expected effectiveness of medical treatment. ${ }^{40}$ Interventions must consider the intergenerational context of Indigenous homelessness, and promote the health of children through investments in families and communities.

This analysis has strengths and limitations. Strengths of the study include a large sample size, structured diagnostic interviews and self-report measures validated against administrative data sources. ${ }^{26}$ Limitations include the possibility that current mental illness or substance use symptoms may have compromised some participant responses. Although participants were asked if they were First Nations, Inuit, Métis and status versus non-status, the current study did not allow for analysis to elicit unique differences between these smaller and distinct groups. It is recommended that further research investigate the differences between First Nations, Métis and Inuit service needs as well as differences between those recognised as status and non-status under the Indian Act to elucidate the diversity of service needs within Indigenous groups. Finally, we relied on self-reported ethnicity and it is possible that Indigenous people may not have self-identified due to concerns related to stigma and discrimination.

\section{Implications}

Pathways leading to homelessness differ meaningfully between Indigenous and non-Indigenous adults who 
Table 3 Logistic regression analysis to estimate the association between Indigenous ethnicity and homelessness, mental and physical illness and service utilisation among Vancouver and Winnipeg 'At Home' participants $(n=1010)$

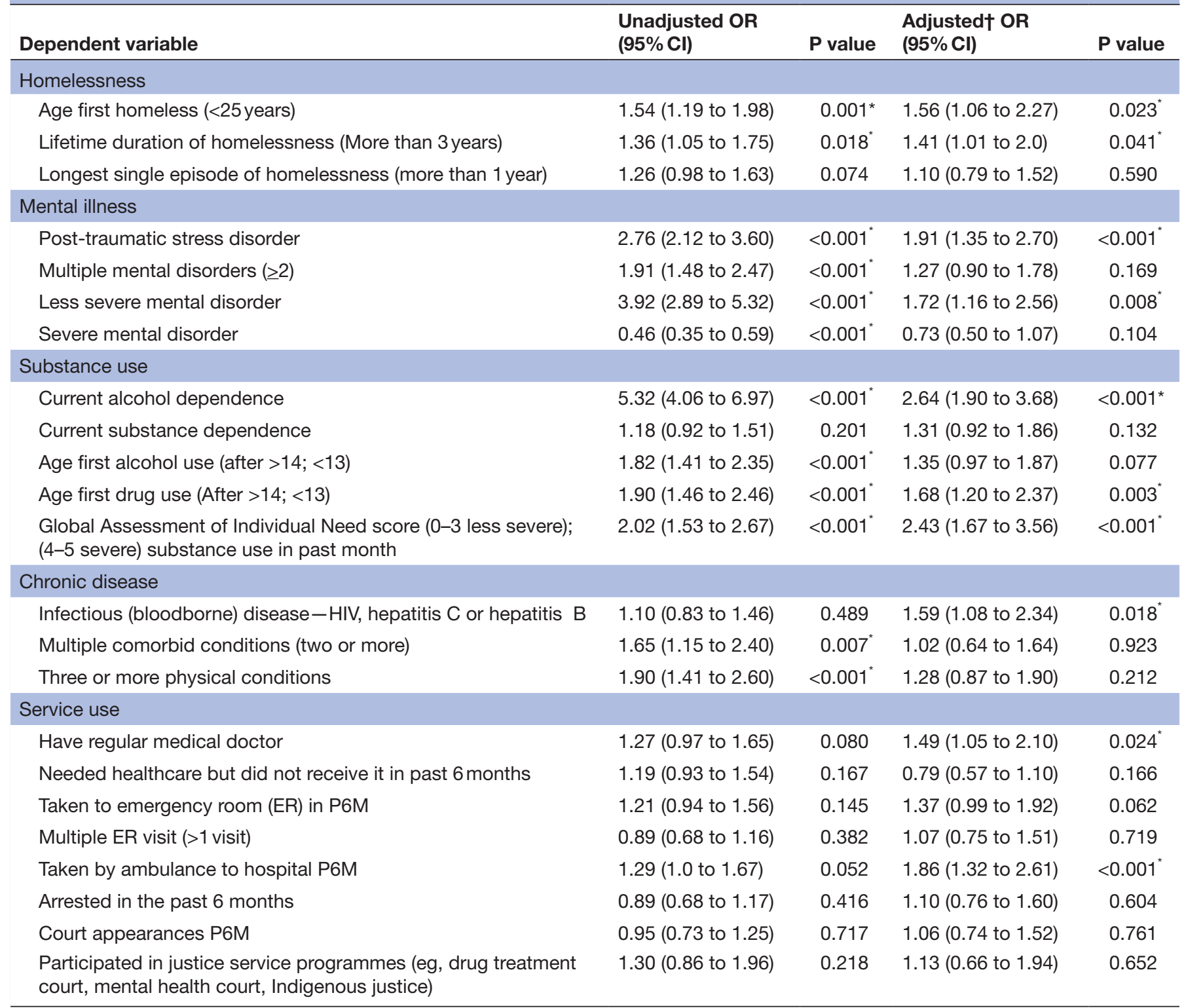

${ }^{*} \mathrm{P}<0.05$.

†Controlled for age (continuous), gender (male, female), need level (high, moderate), marital status (single, other), site (Vancouver, Winnipeg), education (high school or higher, less than high school), have children (under 18).

meet criteria for current homelessness and mental illness. Consistent with our hypotheses, Indigenous participants experienced homelessness at a younger age, were homeless longer, had greater substance-related problems, less formal education, more health emergencies and higher rates of infectious disease than non-Indigenous participants. Indigenous participants were also significantly more likely to satisfy our study's 'mental illness' criterion with PTSD, while non-Indigenous participants were more likely to meet criteria for schizophrenia or bipolar disorder. Our findings are consistent with the view that solutions to Indigenous homelessness-both prevention and treatment-must involve practices that restore social and cultural power to Indigenous communities.
By contrast, non-Indigenous participants showed strong indications for the appropriateness of housing and assertive community treatment, as promised by governments during the era of deinstitutionalisation. Further research is needed to replicate these findings in other regions and where the historical experiences of Indigenous peoples differ based on varying degrees of political and social autonomy and the preservation of cultural practices.

Acknowledgements The research team would like to extend thanks to the participants, service providers and field research teams. The authors also thank the At Home/Chez Soi Project Collaborative.

Contributors $B B$ is the lead in the development of the manuscript. AM carried out the primary statistical analyses. MP, JD, JS and J0 contributed to the editing of the 
manuscript. JMS was the principal investigator, contributed to the research design and writing of the manuscript. All authors read and approved the final manuscript.

Funding This work was supported by a grant to Simon Fraser University from Health Canada and the Mental Health Commission of Canada Grant Number: 2009s0231.

Disclaimer The views expressed herein solely represent the authors.

Competing interests None declared.

Patient consent for publication Not required.

Ethics approval Ethical review and approval was conducted by the Research Ethics Boards at Simon Fraser University, the University of British Columbia and the University of Manitoba with endorsement from the University of Winnipeg.

Provenance and peer review Not commissioned; externally peer reviewed.

Data sharing statement Data are stored at St. Michael's Hospital in Toronto and are available to external investigators who sign a data sharing and use agreement that stipulates the responsibilities associated with transfer of datasets. Carol Adair at the University of Calgary is the data access coordinator.

Open access This is an open access article distributed in accordance with the Creative Commons Attribution Non Commercial (CC BY-NC 4.0) license, which permits others to distribute, remix, adapt, build upon this work non-commercially, and license their derivative works on different terms, provided the original work is properly cited, appropriate credit is given, any changes made indicated, and the use is non-commercial. See: http://creativecommons.org/licenses/by-nc/4.0/.

\section{REFERENCES}

1. Anderson JT, Collins D. Prevalence and causes of urban homelessness among indigenous peoples: a three-country scoping review. Hous Stud 2014;29:959-76.

2. Patrick C. Aboriginal Homelessness in Canada. Toronto, ON: Canadian Homelessness Research Network Press, 2014. https:// www.homelesshub.ca/sites/default/files/AboriginalLiteratureReview. pdf

3. City of Vancouver. Homeless Count. Vancouver, BC, 2018;2018. http://vancouver.ca/people-programs/homeless-count.aspx

4. Statistics Canada. Issue 17-138: 2016 Census: Highlights from the Indigenous People in Canada Release. 2016. https://www2.gov.bc. ca/gov/content/data/statistics/infoline/infoline-2017/17-138-2016census-indigenous-people-canada

5. Wesley-Esquimaux CC, Smolewski M. Historic Trauma and Aboriginal Healing. Ottawa, ON: Aboriginal Healing Foundation, 2004.

6. Bird C, Goulet S, Oelke ND, et al; Aboriginal Homelessness Research Project. Calgary, AB: Aboriginal Friendship Centre of Calgary, 2010. https://www.ucalgary.ca/wethurston/files/wethurston/Aboriginal_ Homelesness GatheringReport March2010.pdf

7. Perissini T. Pathways into Homelessness: Testing the Heterogeneity Hypothesis. In: Hulchanski DJ, Campsie P, Chau S, et al, eds. Finding Home Policy Options for Addressing Homelessness in Canada. Toronto, ON, 2009:1-17.

8. Somers JM, Moniruzzaman A, Rezansoff SN. Migration to the Downtown Eastside neighbourhood of Vancouver and changes in service use in a cohort of mentally ill homeless adults: a 10-year retrospective study. BMJ Open 2016;6:e009043-9.

9. Evans GW, Wells NM, Moch A. Housing and mental health: a review of the evidence and a methodological and conceptual critique. J Soc Issues 2003;59:475-500.

10. Forchuk C, Joplin L, Schofield R, et al. Housing, income support and mental health: points of disconnection. Health Res Policy Syst 2007;5:14-17.

11. Nelson G. Housing for people with serious mental illness: approaches, evidence, and transformative change. Jl of Soc Soc Welf 2010;XXXVII:123-46.

12. Canadian Collaborative Mental Health Initiative. Establishing collaborative initiatives between mental health and primary care services for individuals with substance use disorders. Mississauga, ON: 2006. www.ccmhi.ca

13. Turner D, Goulet S, Oelke ND, et al. Aboriginal homelessness: Looking for a place to belong. Calgary, AB: Aboriginal Friendship Centre of Calgary, 2010.

14. Truth and Reconciliation Commission of Canada. What We Have Learned: Principles of Truth and Reconciliation. Winnipeg, MB: 2015. www.trc.ca

15. John E. Indigenous Resilience, Connectedness and Reunification From Root Causes to Root Solutions. 2016:1-220. http://fns.bc.ca/
wp-content/uploads/2017/01/Final-Report-of-Grand-Chief-Ed-Johnre-Indig-Child-Welfare-in-BC-November-2016.pdf

16. Thistle J. Indigenous Definition of Homelessness in Canada. Toronto, ON: Canadian Observatory on Homelessness Press, 2017.

17. Browne AJ, Smye VL, Rodney P, et al. Access to primary care from the perspective of aboriginal patients at an urban emergency department. Qual Health Res 2011;21:333-48.

18. Browne AJ, Varcoe C, Lavoie J, et al. Enhancing health care equity with Indigenous populations: evidence-based strategies from an ethnographic study. BMC Health Serv Res 2016;16:544.

19. Allan B, Smylie J, Peoples F. Second class treatment: the role of racism in the health and well-being of indigenous peoples in Canada. Toronto, ON 2015.

20. Tang SY, Browne AJ. 'Race' matters: racialization and egalitarian discourses involving aboriginal people in the Canadian health care context. Ethn Health 2008;13:109-27.

21. Rog DJ, Marshall T, Dougherty RH, et al. Permanent supportive housing: assessing the evidence. Psych Serv 2014;65:287-94.

22. Goering PN, Streiner DL, Adair C, et al. The at home/Chez Soi trial protocol: a pragmatic, multi-site, randomised controlled trial of a housing first intervention for homeless individuals with mental illness in five Canadian cities. BMJ Open 2011;1:e000323-3.

23. Somers JM, Patterson ML, Moniruzzaman A, et al. Vancouver At Home: pragmatic randomized trials investigating Housing First for homeless and mentally ill adults. Trials 2013;14:365-20.

24. Strehlau V, Torchalla I, Patterson M, et al. Recruitment and retention of homeless individuals with mental illness in a housing first intervention study. Contemp Clin Trials Commun 2017;7:48-56.

25. Sheehan $D$, Lecrubier $Y$, Sheehan $\mathrm{KH}$, et al. The mini-international neuropsychiatric interview (M. I.N.I.): the development and validation of a structured diagnostic psychiatric interview for DSM-IV and ICD10. J Clin Psych 1998;59:22-3.

26. Somers JM, Moniruzzaman A, Currie L, et al. Accuracy of reported service use in a cohort of people who are chronically homeless and seriously mentally ill. BMC Psychiatry 2016;16:1-7

27. Barker S, Barron N, McFarland BH, et al. A community ability scale for chronically mentally ill consumers: Part II. Applications. Community Ment Health J 1994;30:459-72.

28. Roos LE, Distasio J, Bolton SL, et al. A history in-care predicts unique characteristics in a homeless population with mental illness. Child Abuse Negl 2014;38:1618-27.

29. Patterson ML, Moniruzzaman A, Somers JM. History of foster care among homeless adults with mental illness in Vancouver, British Columbia: a precursor to trajectories of risk. BMC Psych 2015;15:1-11.

30. Aguiar W, Halseth R. Aboriginal peoples and historic trauma: The process of intergenerational transmission: National Collaborating Centre for Aboriginal Health, 2015:1-32. https://www.ccnsa-nccah. $\mathrm{ca} /$ docs/context/RPT-HistoricTrauma-IntergenTransmission-AguiarHalseth-EN.pd

31. Bombay A, Matheson K, Anisman H. Intergenerational trauma: convergence of multiple processes among first nations peoples in Canada. J Aborig Health 2009:1-42.

32. Canadian Centre on Substance Abuse. Substance Abuse in Canada: Youth in Focus. Ottawa, ON: CCSA. 2007:1-51.

33. Kelly M. Prevention of the harmful effects of substance use among aboriginal peoples: an initial review of the research literature. Victoria BC: Centre for Addictions Research of BC, 2007.

34. Miller CL, Strathdee SA, Kerr T, et al. Factors associated with early adolescent initiation into injection drug use: implications for intervention programs. J Adolesc Health 2006;38:462-4.

35. Rawana JS, Ames ME. Protective predictors of alcohol use trajectories among Canadian aboriginal youth. J Youth Adolesc 2012;41:229-43.

36. McCormick RM. Aboriginal traditions in the treatment of substance abuse. Can J Counsel 2000;34:25-32.

37. Thomson M, Vancouver Homeless Count. Vancouver, BC: City of Vancouver, 2016;2016:1-54. http://vancouver.ca/files/cov/homelesscount-2016-report.pdf

38. Fowler PJ, Toro PA, Miles BW. Pathways to and from homelessness and associated psychosocial outcomes among adolescents leaving the foster care system. Am J Public Health 2009;99:1453-8

39. Marshall BD, Kerr T, Livingstone $\mathrm{C}$, et al. High prevalence of HIV infection among homeless and street-involved aboriginal youth in a Canadian setting. Harm Reduct J 2008;5:35-5.

40. Monette LE, Rourke SB, Gibson K, et al. Inequalities in determinants of health among aboriginal and Caucasian persons living with HIV/ AIDS in Ontario: results from the positive spaces, healthy places study. Can J Public Health 2011;102:216-9. 